
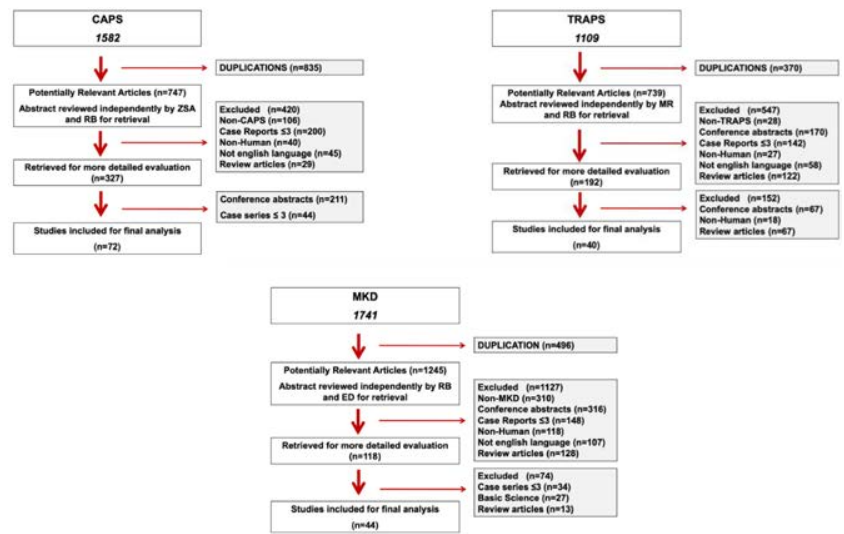

Figure 1. Flow-charts of systematic review for CAPS, TRAPS and MKD.

References:

[1] van der Heijde D, Aletaha D, Carmona L, et al 2014 Update of the EULAR standardised operating procedures for EULAR-endorsed recommendations Annals of the Rheumatic Diseases 2015;74:8-13.

[2] Gattorno M, Hofer M, Federici S, Vanoni F, Bovis F, Aksentijevich I, Anton J, Arostegui JI, Barron K, Ben-Cherit E, Brogan PA, Cantarini L, Ceccherini I, De Benedetti F, Dedeoglu F, Demirkaya E, Frenkel J, Goldbach-Mansky R, Gul A, Hentgen V, Hoffman H, Kallinich T, Kone-Paut I, Kuemmerle-Deschner J, Lachmann HJ, Laxer RM, Livneh A, Obici L, Ozen S, Rowczenio D, Russo R, Shinar Y, Simon A, Toplak N, Touitou I, Uziel Y, van Gijn M, Foell D, Garassino C, Kastner D, Martini A, Sormani MP, Ruperto N; Eurofever Registry and the Paediatric Rheumatology International Trials Organisation (PRINTO). Classification criteria for autoinflammatory recurrent fevers. Ann Rheum Dis. 2019 Aug;78(8):1025-1032.

Disclosure of Interests: Roberta Berard: None declared, micol romano: None declared, Zehra Serap Arici: None declared, David Piskin: None declared, Olcay Jones: None declared, Karen Durrant: None declared, Raphaela Goldbach-Mansky: None declared, Marco Gattorno Consultant of: Sobi, Novartis, Speakers bureau: Sobi, Novartis, Erkan Demirkaya: None declared

DOI: 10.1136/annrheumdis-2020-eular.6023

\section{FRI0483 SUBCLINICAL INFLAMMATION AND RELATED PARAMETERS IN PATIENTS WITH FAMILIAL MEDITERRANEAN FEVER}

M. T. Duruöz ${ }^{1}$, N. Öz ${ }^{1}$, A. Ozer ${ }^{1}$, H. H. Gezer ${ }^{1}$, D. Erdem Gürsoy ${ }^{1}$, S. Acer Kasman ${ }^{1} .^{1}$ Marmara University Pendik Training and Research Hospital, Physical Treatment and Rehabilitation Rheumatology, Istanbul, Turkey

Background: Familial Mediterranean Fever (FMF), which is more common in groups in the Mediterranean basin, is a monogenic autoinflammatory disease characterized by recurrent attacks of febrile peritonitis, pleuritis and arthritis. Objectives: In this study, we aimed to investigate the clinical, demographic and genotypic features that may be associated with subclinical inflammation in FMF and to determine the related parameters with subclinical inflammation.

Methods: FMF patients according to the Tel-Hashomer criteria were included into the study. The demographic characteristics of the patients, duration of the disease, concomitant diseases, MEFV genotype mutation, colchicine use and resistance were collected. Acute-phase reactants such as white blood cell count, erythrocyte sedimentation rate, and C-reactive protein levels during the attacks and attack-free periods were noted. Subclinical inflammation was defined as the continuation of the acute phase response (CRP) between episodes. We divided study population into two groups as; patients with or without subclinical inflammation (Group 1 and Group 2, respectively) and these group were compared with the parameters described above. Patients with infectious disease (viral or bacterial) in the past two months were excluded from the study

Results: Eigthy patients (72.5\% female) with mean age 37.1 SD 11.2 years were recruited into the study. Twenty-three $(28.7 \%)$ patients were determined with subclinical inflammation. Group 1 had significantly higher rate of concomitant rheumatic disease(i.e spondyloarthropathy), erythrocyte sedimentation rate and MEFV homozygous mutation compared with Group 2 ( $p<0.05$, for each). Disease duration, months PRASS score, FMF quality of life, age at onset of symptoms, family history of FMF, response to colchicine, attack time, attack in the last 6 , delay in diagnosis parameters were not significantly different between groups $(p>0.05)$

Conclusion: FMF patients whose elevated erythrocyte sedimentation rate and MEFV homozygous mutation should be closely monitored for subclinical inflammation even during attack-free periods. Concomitant disease should be detected in FMF patients with subclinical inflammation.

\section{References:}

[1] Shinawi M, Brik R, Kepten I, Berant M, Gersoni B. Familial Mediterranean fever: high gene frequency and heterogenous disease among Israeli-Moslem Arab population. J Rheumatol 2000;27:1492-5

[2] Bayram MT, Cankaya T, Bora E, Kavukçu S, Ülgenalp A, Soylu A, Türkmen M. Risk factors for subclinical inflammation in children with Familial Mediterranean fever. Rheumatol Int. 2015 Aug;35(8):1393-8.

Table 1: Demographic and clinical features of the patients with familial Mediterranean fever

\begin{tabular}{|c|c|c|c|}
\hline & $\begin{array}{l}\text { Without Subclinical } \\
\text { inflamation } \\
n=(57)\end{array}$ & $\begin{array}{c}\text { With Subclinical } \\
\text { inflamation } \\
n=(23)\end{array}$ & $\begin{array}{c}P \\
\text { value }\end{array}$ \\
\hline Age (years; mean SD) & 37,78 SD 13,22 & 36,82 SD 10,49 & 0.987 \\
\hline Female, gender, $\mathrm{n}(\%)$ & $45(\% 78)$ & $13(\% 56)$ & 0.055 \\
\hline $\begin{array}{l}\text { Disease duration } \\
\text { (month; mean SD) }\end{array}$ & 255,3 SD 195,1 & 180,2 SD 121,1 & 0.191 \\
\hline $\begin{array}{l}\text { PRASS score } \\
\text { (mean SD) }\end{array}$ & 6,08 SD 2,15 & 5,36 SD 1,59 & 0.147 \\
\hline $\mathrm{BMi}, \mathrm{kg} / \mathrm{m}^{2}$ & 26,12 SD 4,8 & 32,13 SD 28,48 & 0.629 \\
\hline Current smoking status (\%) & $17(\% 29)$ & $3(\% 13)$ & 0.067 \\
\hline $\begin{array}{l}\text { Age at onset of symptoms (month; } \\
\text { mean SD) }\end{array}$ & 15,69 SD 9,41 & 17,28 SD 10,34 & 0.54 \\
\hline Family history of FMF(\%) & $37(\% 64)$ & $18(\% 78)$ & 0.295 \\
\hline Response to colchicine(\%) & $6(\% 10)$ & $4(\% 17)$ & 0.462 \\
\hline $\begin{array}{l}\text { Attack time } \\
\text { (day; mean SD) }\end{array}$ & $1,9 \mathrm{SD} 1,1$ & 2,26 SD 1,4 & 0,523 \\
\hline Attack in the last 6 months (mean SD) & 2,79 SD 3,1 & 4,56 SD 5,5 & 0,184 \\
\hline $\begin{array}{l}\text { FMF quality of life } \\
\text { (mean SD) }\end{array}$ & 31,5 SD 13,6 & 25.7 SD 16,4 & 0,130 \\
\hline Delay in diagnosis(month; mean SD) & 12,29 SD 10,9 & 14,3 SD 14,9 & 0,840 \\
\hline
\end{tabular}

Disclosure of Interests: None declared

DOI: 10.1136/annrheumdis-2020-eular.4801

\begin{tabular}{l|l}
\hline FRI0484 & SAFETY PROFILE, CLINICAL AND RADIOLOGICAL \\
EFFICACY OF ANAKINRA, TARGETED AND \\
COMBINED TREATMENT IN ERDHEIM-CHESTER \\
DISEASE
\end{tabular}

N. Farina ${ }^{1}$, C. Campochiaro ${ }^{1}$, A. Tomelleri ${ }^{1}$, G. De Luca ${ }^{1}$, G. Cavalli ${ }^{1}$, L. Dagna ${ }^{1}$ ${ }^{1}$ IRCCS San Raffaele Hospital, Unit of Immunology, Rheumatology, Allergy and Rare Diseases, Milan, Italy

Background: Erdheim-Chester disease (ECD) is a rare non-Langerhans histiocytosis. Combined treatment with anakinra (ANK) and targeted MAPK-inhibiting therapies (vemurafenib - VMF - or cobimetinib - CBM) has been recently used to treat severe cases of ECD.

Objectives: To evaluate the safety and the clinical and radiological efficacy of ANK, targeted and combined treatments in ECD patients in a real-world setting

Table 1. Disease characteristics and therapy-related adverse reactions of Erdheim-Chester patients treated with vemurafenib, cobimetinib and/ or anakinra.

Vemurafenib $(n=19) \quad$ Cobimetinib $(n=10) \quad$ Anakinra $(n=12)$

Clinical Manifestations Retroperitoneal Pleuropulmonary Neurological and/or orbital

Adverse reactions

Renal

Cutaneous

Systemic Inflammation

Cardiovascular

Gastrointestinal

Haematological

Herpes Zoster 
Table 2. Efficacy and discontinuation rates of monotherapy and combined treatment in Erdheim-Chester disease. * Referred to imaging re-staging.

\begin{tabular}{|c|c|c|c|c|c|c|c|}
\hline & $\begin{array}{l}\text { Therapy } \\
\text { courses }\end{array}$ & $\begin{array}{l}\text { Clinical } \\
\text { efficacy }\end{array}$ & $\begin{array}{l}\text { Improving } \\
\text { disease * }\end{array}$ & Stable disease * & $\begin{array}{c}\text { Progressive } \\
\text { disease * }\end{array}$ & $\begin{array}{l}\text { Discontinuation } \\
\text { due to toxicity }\end{array}$ & $\begin{array}{l}\text { Discontinuation } \\
\text { due to inefficacy }\end{array}$ \\
\hline Vemurafenib & 19 & $93 \%$ & $73 \%$ & $27 \%$ & $0 \%$ & $37 \%$ & $0 \%$ \\
\hline Cobimetinib & 6 & $80 \%$ & $100 \%$ & $0 \%$ & $0 \%$ & $50 \%$ & $0 \%$ \\
\hline Anakinra & 10 & $86 \%$ & $0 \%$ & $25 \%$ & $75 \%$ & $20 \%$ & $40 \%$ \\
\hline Vemurafenib + Anakinra & 3 & $100 \%$ & $100 \%$ & $0 \%$ & $0 \%$ & $0 \%$ & $0 \%$ \\
\hline Cobimetinib + Anakinra & 4 & $100 \%$ & $100 \%$ & $0 \%$ & $0 \%$ & $25 \%$ & $0 \%$ \\
\hline
\end{tabular}

Methods: ECD patients followed at our Center who received at least one targeted therapy and/or ANK were selected. Data about disease characteristics, adverse reactions, clinical and radiological efficacy (by means of CT, CT/PET, MRI when appropriate and repeated 6 months apart) were collected.

Results: Among the 48 ECD patients followed up at our Center, 27 were treated with at least one drug between VMF and CBM, accounting for a total of 22 and 10 therapy courses respectively. 12 patients were treated with ANK as monotherapy or combination treatment (a total of 17 therapy courses). Disease characteristics and adverse reactions to the treatments are shown in Table 1. All 3 drug proved to have a high clinical efficacy (Table 2). No patient treated with VMF or CBM showed radiological progression neither discontinued treatment due to inefficacy. Conversely, $75 \%$ of patients receiving ANK monotherapy showed progression at imaging re-staging and inefficacy was the main discontinuation cause. ANK showed the lowest incidence of adverse reactions. Drug toxicity was instead the only reason for discontinuation of targeted monotherapies. The combined approach had a clinical efficacy in all cases and it was always associated with imaging improvement. One patient treated with ANK and CBM discontinued the therapy due to drug-related toxicity. No patient receiving both VMF and ANK experienced drug-related toxicities; in these patients ANK led to a reduction in mean acute phase reactants levels and concomitant prednisone dose (Figure 1)

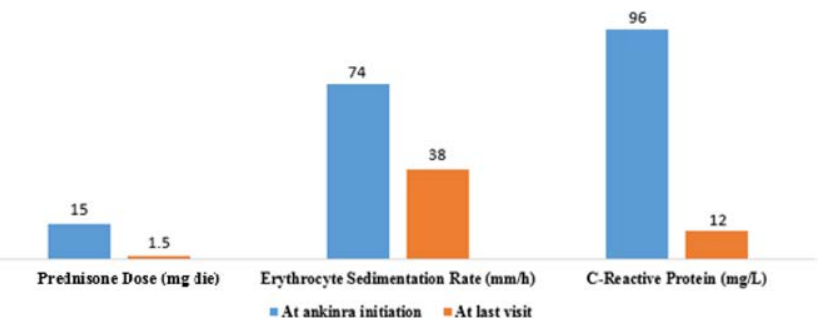

Figure 1. Mean acute phase reactant levels and concomitant prednisone dose in Erdheim-Chester disease patients treated with vemurafenib before and after the initiation of anakinra.

Conclusion: Combined treatment had a higher clinical and radiological efficacy than ANK monotherapy and led to a reduction in targeted therapies-related toxicities, acute phase reactant levels and concomitant prednisone dose.

References:

[1] Efficacy and improved tolerability of combination therapy with interleukin-1 blockade and MAPK pathway inhibitors for the treatment of Erdheim-Chester disease; Campochiaro et al; Ann Rheum Dis. 2019; 10.1136/ annrheumdis-2019-216610

Disclosure of Interests: Nicola Farina: None declared, Corrado Campochiaro Speakers bureau: Novartis, Pfizer, Roche, GSK, SOBI, Alessandro Tomelleri: None declared, Giacomo De Luca Speakers bureau: SOBI, Novartis, Celgene, Pfizer, MSD, Giulio Cavalli Speakers bureau: SOBI, Novartis, Pfizer, Lorenzo Dagna Grant/research support from: Abbvie, BMS, Celgene, Janssen, MSD, Mundipharma Pharmaceuticals, Novartis, Pfizer, Roche, SG, SOBI, Consultant of: Abbvie, Amgen, Biogen, BMS, Celltrion, Novartis, Pfizer, Roche, SG, and SOBI

DOI: 10.1136/annrheumdis-2020-eular.3259

\section{FRI0485 RISK OF PROGRESSION OF IDIOPATHIC PULMONARY FIBROSIS TO CONNECTIVE TISSUE DISEASE}

B. Ghang ${ }^{1}$, S. H. Nam², Y. G. Kim², B. Yoo², C. K. Lee'2. 'Jeju National University School of Medicine, Jeju National University Hospital, Rheumatology, Jeju, Korea, Rep. of (South Korea); ${ }^{2}$ Asan Medical Center, Rheumatology, Seoul, Korea, Rep. of (South Korea)
Background: Connective tissue disease (CTD) may be observed during the course of idiopathic pulmonary fibrosis (IPF). However, clinical factors associated with the development of CTD in patients with IPF have not yet been identified. These factors might be valuable clues for determining the pathogenesis of pulmonary fibrosis in patients with CTD. We hypothesize that some IPF patients have a clinically significant association with autoimmunity, and that autoantibodies are important biomarkers for identifying these patients.

Objectives: Based on this hypothesis, we investigated whether the serology criteria (anti-neutrophil cytoplasmic antibody (ANCA) or autoantibodies that met the serology criteria for interstitial pneumonitis with autoimmune features (IPAF)) were associated with the development of CTD during the clinical course of IPF in the patients from our previous study(1), with a particular focus on which antibodies have a significant association with the development of CTD.

Methods: We retrospectively reviewed the records of 527 patients with a first diagnosis of IPF between January 2007 and March 2014, and investigated the length of time from first visit to the clinic for IPF diagnosis (baseline) to CTD diagnosis by an expert rheumatologist in patients with IPF. Multivariable Cox proportional-hazards models with backward elimination were used to investigate the risk factors for the development of CTD.

Results: CTD developed in 15 patients at a median of 2.1 years (range 1.2 to 4.8) after IPF diagnosis. All these patients had ANCA or autoantibodies that met the serology criteria for IPAF. A significant number of IPF patients with high titers of RF, ACPA or MPO-ANCA tested at first visit to the clinic progressed to CTD(Figure 1). Survival duration for IPF patients with progression to CTD was $5.3[3.8 ; 6.7]$ years, which was significantly longer than for the IPF patients without progression to CTD $(2.9[1.7 ; 4.8], \mathrm{p}=0.001)$. Independent risk factors for development of CTD in IPF patients included female gender (adjusted haz ard ratio $(\mathrm{HR}) 5.319, \mathrm{p}=0.0082$ ), titer of rheumatoid factor (RF) (adjusted HR 1.006, $p=0.022$ ), titer of anti-citrullinated protein antibody (ACPA) (adjusted HR 1.009, $p=0.0011$ ), and titer of myeloperoxidase (MPO) ANCA (adjusted HR 1.02, $p<0.0001$ )

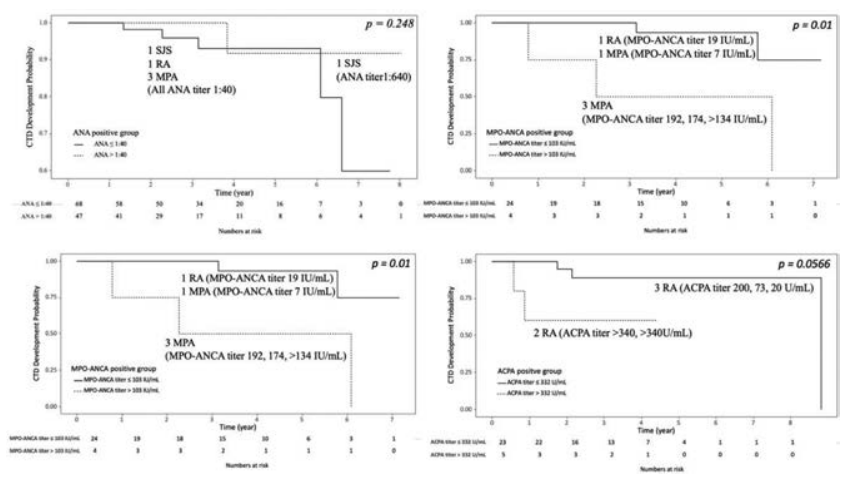

Figure 1. Connective tissue disease development in each autoantibody positive IPF patient ACPA = anti-citrullinated protein antibody; ANA = antinuclear antibody; CTD = connective tissue disease; $\mathrm{MPA}=$ microscopic polyangiitis; $\mathrm{PAN}=$ polyarteritis nodosa; $\mathrm{RA}=$ rheumatoid arthritis; RF = rheumatoid factor; UCTD = Undifferentiated connective tissue disease; $\mathrm{SjS}=$ Sjögren's syndrome.

Conclusion: We observed development of CTD in IPF patients with ANCA or autoantibodies that met the IPAF serology criteria. Among these autoantibodies, RF, ACPA, and MPO-ANCA were significantly associated with the developmen of CTD in IPF patients. Progression to CTD is uncommon in IPF patients, but a significant number of IPF patients with high titers of RF, ACPA or MPO-ANCA progressed to connective tissue disease. IPF with high titers of RF, ACPA or MPO-ANCA might be the initial clinical manifestation of connective tissue disease. Further studies are needed to investigate the role of RF, ACPA, and MPOANCA in development of pulmonary fibrosis. 